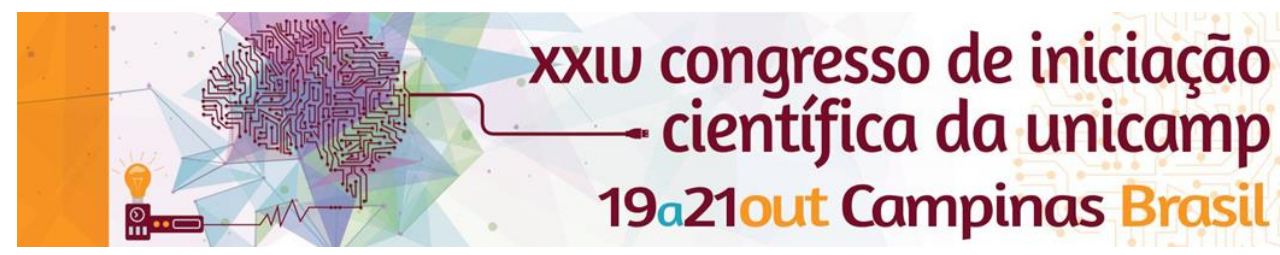

\title{
ADOLESCENTS FOOD INTAKE OF GLUTEN: A POPULATION-BASED STUDY IN CAMPINAS, SP.
}

\section{Ana Carolina M. F. Rocha*, Caroline D. Capitani, Daniela Assumpção, Marilisa B. A. Barros.}

\begin{abstract}
Cereals consumption is encouraged for a healthy eating, however, some varieties have gluten in their composition, that could be toxic to people who present some pathology related to its ingestion. The aim of this study was to evaluate the intake of foods with gluten in adolescents in Campinas, SP.
\end{abstract}

\section{Key words:}

Adolescents, Gluten, Food Consumption.

\section{Introduction}

The current high the amount of processed food consumption increased the population gluten intake. A higher incidence of gluten-related diseases may be related to baking techniques that requires less time for dough fermentation, increasing its gluten concentration ${ }^{1}$.

Celiac Disease is a gluten-related disease that affects about $1 \%$ of global population ${ }^{2}$ and its incidence has significantly increased over the years ${ }^{3}$. Therefore the aim of this study was evaluate foods with gluten intake by adolescents according to demographic, socioeconomic and health-related behaviors.

\section{Results and Discussion}

The study was a cross-sectional population-based study cluster sampling and by two stages, held in Campinas, São Paulo, as part of ISA-Camp (2008-2009). Male and female adolescents $(n=929)$ aged 10 to 19 years were evaluated by dietary intake was estimated by 24-hour dietary recall. Prevalence and adjusted prevalence ratios were calculated using Poisson Multiple Regression.

There was a higher prevalence of gluten intake by girls, endorsing data from Pesquisa Nacional de Saúde do Escolar (2008-09) which states that girls eat more cookies and snacks than boys.

The number of household equipment $(p<0.05)$ was significantly associated with gluten consumption.

Lower frequency consumption of cooked vegetables, milk and beans, was associated to higher gluten ingestion $(p<0.05)$. Adolescents with lower vegetable and fruit ingestion are used to replace these fresh foods for high saturated fat and low nutrients snacks. Besides that, lower prevalence of gluten intake was observed in individuals from other states, compared to Campinas SP natives, this is due to different eating patterns of each part of the country.

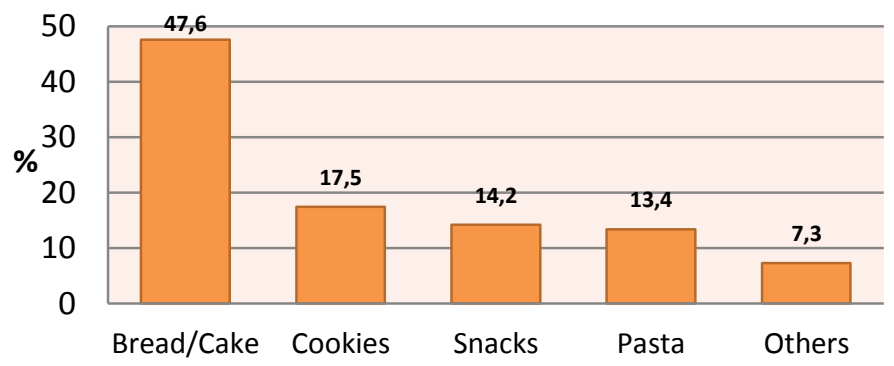

Image 1. Foods containing gluten intake frequency by adolescents living in Campinas, SP.

\section{Conclusions}

The prevalence of foods with gluten intake was higher in female adolescents of high socioeconomic status and that consume less vegetables, milk and beans.

Grains, especially whole, contribute to a healthy diet and should not be removed from the diet without medical advice.

\section{Acknowledgement}

ISACamp, which provided data for the preparation of this research and PIBIC, that granted the scholarship.

${ }^{1}$ SOUZA, A. M. et al. Alimentos mais consumidos no Brasil: Inquérito Nacional de Alimentação 2008-2009. Rev. Saúde Pública, São Paulo , v. 47, supl. 1, p. 190s-199s, Fev. 2013

${ }^{2}$ LUDVIGSSON, J. F. et al. The Oslo definitions for coeliac disease and related terms. Gut., v. 62, n. 1, p. 43-52, Jan 2013.

${ }^{3}$ MANSUETO, P. et al. Non-Celiac Gluten Sensitivity: Literature Review. Journal of the American College of Nutrition, v. 33:1, p. 39s-54s, Fev. 2014. 